Wright State University

CORE Scholar

8-1-2007

\title{
Thermally Driven Defect Formation and Blocking Layers at Metal- ZnO Interfaces
}

\author{
H. L. Mosbacker \\ C. Zgrabik \\ M. J. Hetzer \\ A. Swain \\ David C. Look \\ Wright State University - Main Campus, david.look@wright.edu
}

See next page for additional authors

Follow this and additional works at: https://corescholar.libraries.wright.edu/physics

Part of the Physics Commons

\section{Repository Citation}

Mosbacker, H. L., Zgrabik, C., Hetzer, M. J., Swain, A., Look, D. C., Cantwell, G., Zhang, J., Song, J. J., \& Brillson, L. J. (2007). Thermally Driven Defect Formation and Blocking Layers at Metal-ZnO Interfaces. Applied Physics Letters, 91 (7), 72102.

https://corescholar.libraries.wright.edu/physics/94

This Article is brought to you for free and open access by the Physics at CORE Scholar. It has been accepted for inclusion in Physics Faculty Publications by an authorized administrator of CORE Scholar. For more information, please contact library-corescholar@wright.edu. 


\section{Authors}

H. L. Mosbacker, C. Zgrabik, M. J. Hetzer, A. Swain, David C. Look, G. Cantwell, J. Zhang, J. J. Song, and L. J. Brillson 


\title{
Thermally driven defect formation and blocking layers at metal-ZnO interfaces
}

\author{
H. L. Mosbacker, ${ }^{\text {a) }}$ C. Zgrabik, and M. J. Hetzer \\ Department of Physics, The Ohio State University, Columbus, Ohio 43210
}

A. Swain

Columbus School for Girls, Bexley, Ohio 43209

D. C. Look

Semiconductor Research Center, Wright State University, Dayton, Ohio 45433

and Materials and Manufacturing Directorate, Air Force Research Laboratory, WPAFB, Ohio 45433

G. Cantwell, J. Zhang, and J. J. Song ${ }^{\text {b) }}$

ZN Technology, Inc., 910 Columbia St., Brea, California 92821

L. J. Brillson ${ }^{\mathrm{c})}$

Departments of Electrical and Computer Engineering, The Ohio State University, Columbus, Ohio 43210

(Received 24 May 2007; accepted 26 July 2007; published online 16 August 2007)

\begin{abstract}
The authors used depth-resolved cathodoluminescence spectroscopy and current-voltage measurements to probe the temperature-dependent formation of native point defects and reaction layers at metal- $\mathrm{ZnO}$ interfaces and their effect on transport properties. These results identify characteristic defect emissions corresponding to metal-Zn alloy versus oxide formation. Au alloys with $\mathrm{Zn}$ above its eutectic temperature, while Ta forms oxide blocking layers that reduce current by orders of magnitude at intermediate temperatures. Defects generated at higher temperatures and/or with higher initial defect densities for all interfaces produce Ohmic contacts. These reactions and defect formation with annealing reveal a thermodynamic control of blocking versus Ohmic contacts. () 2007 American Institute of Physics. [DOI: 10.1063/1.2772664]
\end{abstract}

$\mathrm{ZnO}$ is a promising material for next-generation optoand microelectronics. ${ }^{1,2}$ However, several technological hurdles remain before devices are realized, including the fabrication of thermally stable rectifying and Ohmic contacts. Previously, the authors showed how oxygen plasma processing removes adsorbates, subsurface hydrogen, and deep levels to improve Schottky barriers. ${ }^{3,4}$ In this letter, we emphasize the importance of thermally induced interface chemical interactions in forming blocking layers and defects. These interactions depend on the metal-ZnO bonding, the annealing temperature, and the initial bulk native defect concentration. Depth-resolved cathodoluminescence spectroscopy (DRCLS) measurements reveal two classes of metal$\mathrm{ZnO}$ reactions that determine the contacts' current-voltage $(I-V)$ properties and thermal stability. DRCLS emissions at 2.1 vs $2.5 \mathrm{eV}$ appear characteristic of $\mathrm{Zn}$ - versus O-deficient native point defects based on alloy versus oxide formation, respectively. High work function metals such as $\mathrm{Au}, \mathrm{Pt}$, and Pd form high Schottky barriers that degrade with thermally induced alloying. Oxide-forming metals such as $\mathrm{Ta}, \mathrm{Al}$, and Ir can form interfacial layers at intermediate temperatures that block transport with both forward and reverse biases. Higher temperatures degrade these blocking layers. Higher initial bulk native defect densities promote additional reactions and defects that accelerate these effects.

\footnotetext{
a) Also at Department of Electrical and Computer Engineering, The Ohio State University, Columbus, $\mathrm{OH}$.

${ }^{b)}$ Also at Department of Electrical and Computer Engineering, University of California, San Diego, CA.

c) Also at Department of Physics, The Ohio State University, Columbus, OH; electronic mail: brillson.1@osu.edu
}

The DRCLS, plasma processing, and metallization techniques have been described previously. ${ }^{5}$ We exposed several bulk $\mathrm{ZnO}$ single crystals from two vendors to a $20 \%$ $\mathrm{O}_{2}-80 \% \mathrm{He}$ remote plasma for $1 \mathrm{~h}$, then patterned sets of 5-6 each, $30 \mathrm{~nm}$ thick, and $0.4 \mathrm{~mm}$ diameter contacts of

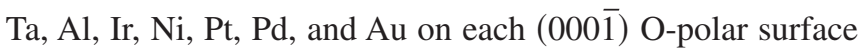
using filament evaporation without intervening air exposure or electron beam evaporation following air exposure. The $\mathrm{ZnO}$ substrates varied in growth technique, deep level defect density, and near band edge (NBE) emission intensity. Depending on the intensity ratio $R$ of deep level versus NBE emissions, these crystals are termed "high" (e.g., $R \approx 1$ ) or "low" (e.g., $R \sim 10^{-3}$ ) defect. A JEOL $7800 \mathrm{~F}$ ultrahigh vacuum scanning electron microscope provided spatially localized excitation through the metal diodes of the $\mathrm{ZnO}$ interfaces versus the bare surface next to the diodes. For incident electron beam energies $E_{B}=2,5,10$, and $20 \mathrm{keV}$, Monte Carlo simulations of the electron cascade yield depths of peak electron-hole pair creation $U_{0} \sim 55,85,330$, and $990 \mathrm{~nm}$, respectively, below the free $\mathrm{ZnO}$ surface. Peak excitation through $30 \mathrm{~nm}$ metal overlayers for $E_{B}=2,5,10$, and $20 \mathrm{keV}$ corresponds to $U_{0} \sim-20$ (inside the metal), 40, 270, and $960 \mathrm{~nm}$, respectively, varying slightly with metal density. For most metals, a $5 \mathrm{keV}$ beam through the 30 -nm-thick metal overlayer and a $2 \mathrm{keV}$ beam into the bare $\mathrm{ZnO}$ surface have comparable $U_{0}$. Optical transmission through the various metals showed negligible variation across the 1.4-6 eV spectral range. Schottky barriers and ideality factors were extracted from $I-V$ curves using thermionic field emission analysis. We measured $10 \mathrm{~K}$ DRCL spectra and $I-V$ characteristics of patterned surfaces following $1 \mathrm{~h}$ annealing at 


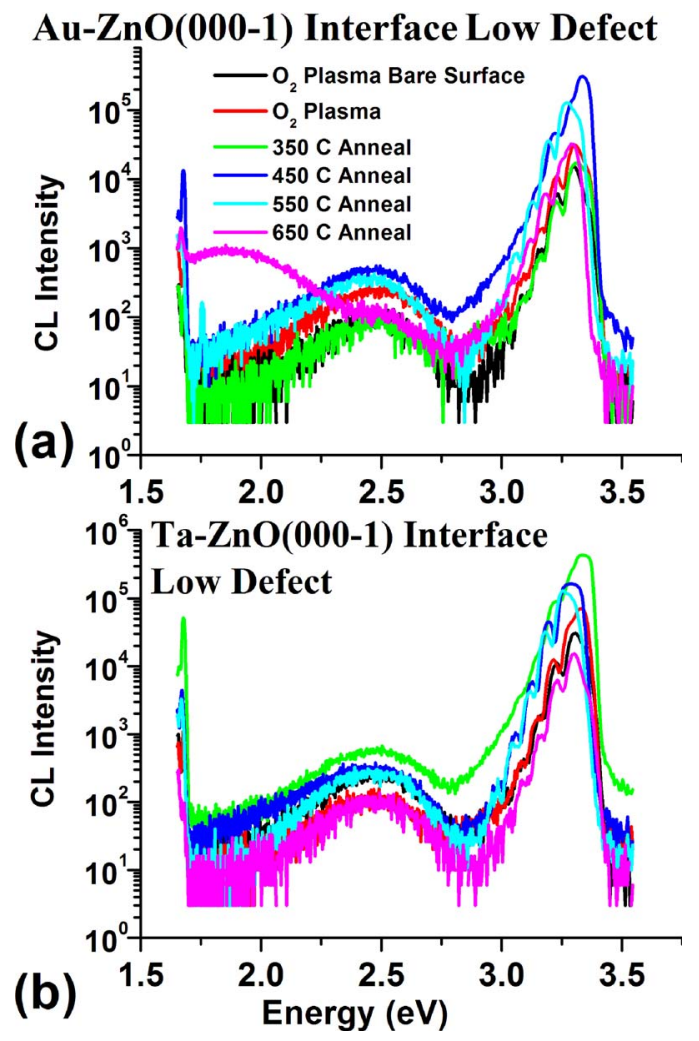

FIG. 1. (Color online) $5 \mathrm{keV}$ DRCLS of $30 \mathrm{~nm}$ (a) Au and (b) Ta deposited on low defect $(000 \overline{1}) \mathrm{ZnO}$. For Au, annealing induces only slight changes for $T<650{ }^{\circ} \mathrm{C}$ but a large $\sim 2 \mathrm{eV}$ peak at $650{ }^{\circ} \mathrm{C}$. Initial Ta deposition triples $2.5 \mathrm{eV}$ emission, but annealing induces no $\sim 2 \mathrm{eV}$ emission or further 2.5 growth.

temperatures up to $650{ }^{\circ} \mathrm{C}$ in a tube furnace with 1 atm flowing Ar.

Previously, we showed that metals induce native point defects at $\mathrm{ZnO}$ interfaces with CL emissions at 2.1, 2.5, and $\sim 3 \mathrm{eV}^{5}$ similar to energies reported previously for $\mathrm{Zn}$-rich or poor crystal growth. ${ }^{6}$ Among possible native defects, $\mathrm{Zn}$ and $\mathrm{O}$ vacancies are predicted to be the most energetically favorable ${ }^{7}$ positron annihilation ${ }^{8}$ and electron paramagnetic resonance ${ }^{9,10}$ spectroscopies associate the 2.1 and $2.5 \mathrm{eV}$ optical transitions with $\mathrm{Zn}$ and $\mathrm{O}$ vacancies. Elevated temperatures produce large changes in these emissions, depending on the metal and the bulk native defect concentration. Figure 1 presents DRCL spectra for (a) Au and (b) Ta on low defect $\mathrm{ZnO}(000 \overline{1})$. Annealing up to $T=550{ }^{\circ} \mathrm{C}$ leaves the $\mathrm{Au} / \mathrm{ZnO}$ $I(2.5 \mathrm{eV}) / I(\mathrm{NBE})$ ratio nearly unchanged and introduces no new spectra features. However, at $650{ }^{\circ} \mathrm{C}$, new emission appears at $\sim 2 \mathrm{eV}$ that dominates the deep level spectra. Significantly, Au forms a eutectic with $\mathrm{Zn}$ at $625^{\circ} \mathrm{C}$ (Ref. 11) and an $\sim 2.1 \mathrm{eV}$ emission has been reported with $\mathrm{Zn}$ deficient growth, ${ }^{6}$ suggesting $\mathrm{Au}-\mathrm{Zn}$ alloying that extracts $\mathrm{Zn}$ from the substrate. In contrast, $I(2.5 \mathrm{eV}) / I$ (NBE) increases by more than three times with initial Ta deposition ${ }^{5}$ but adds no emission at $\sim 2$ or $2.5 \mathrm{eV}$ up to $650{ }^{\circ} \mathrm{C}$.

$I-V$ curves display electrical features that correlate with these DRCL spectra and reflect thermal stability up to $550{ }^{\circ} \mathrm{C}$ for low defect $\mathrm{ZnO}$. Figure 2(a) shows that $\mathrm{Au}$ diodes remain strongly rectifying (barrier $\Phi_{B}=0.46 \mathrm{eV}$ and ideality factor $n=4.30$ ) with increased Schottky barrier $\Phi_{B}$ $=0.54 \mathrm{eV}$ and lower ideality $n=1.47$ following a $450{ }^{\circ} \mathrm{C}$ annealing. This is in contrast to thermal instability reported

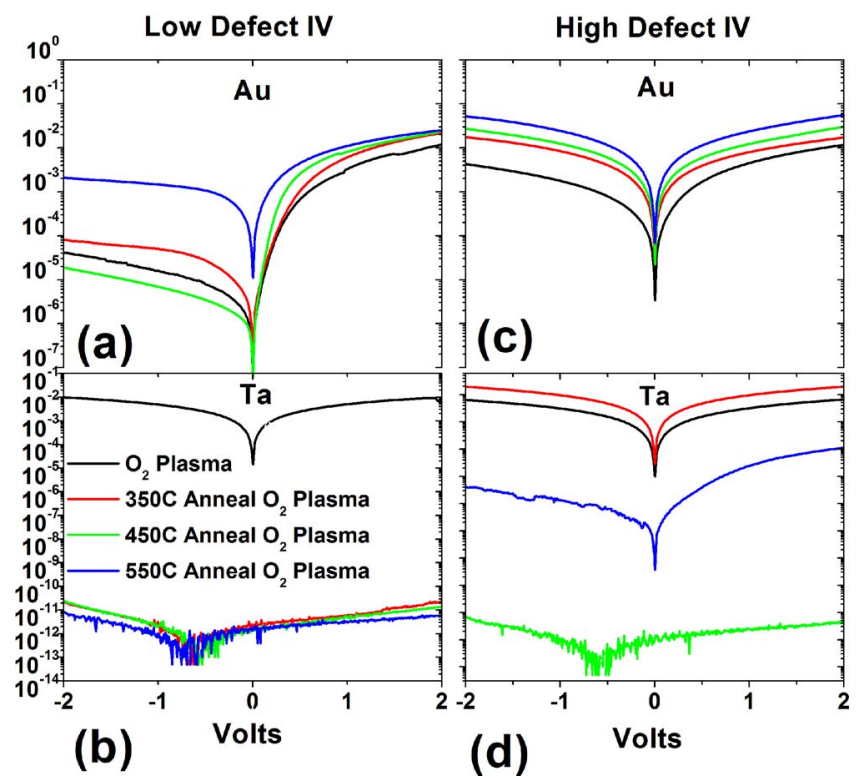

FIG. 2. (Color online) Low defect $I-V$ characteristics show (a) $\mathrm{Au}-\mathrm{ZnO}$ Schottky contacts improving at $T=450{ }^{\circ} \mathrm{C}$ and remaining rectifying up to a $550{ }^{\circ} \mathrm{C}$ annealing and (b) annealed Ta contacts blocking and stable up to $550^{\circ} \mathrm{C}$. High defect $I-V$ characteristics show (c) Au Schottky barrier steadily degrading starting at $350{ }^{\circ} \mathrm{C}$ and (d) Ta contacts that become blocking at $450{ }^{\circ} \mathrm{C}$ with leakage increasing at $550{ }^{\circ} \mathrm{C}$. Both metals show lower thermal stability vs low defect $\mathrm{ZnO}$.

elsewhere $^{12}$ for $\mathrm{Au}-\mathrm{ZnO}$ contacts and, significantly, to our high defect $\mathrm{ZnO}$ studies. At $650{ }^{\circ} \mathrm{C}, \Phi_{B}$ degrades to $0.43 \mathrm{eV}$ with $n=1.80$.

Figure 2(b) illustrates the formation of stable, blocking $\mathrm{Ta}-\mathrm{ZnO}$ contacts. Initially Ohmic, they become blocking following a $350{ }^{\circ} \mathrm{C}$ annealing and remain blocking at higher temperatures. Leakage currents are $<10^{-11} \mathrm{~A}(1.6$ $\left.\times 10^{-10} \mathrm{~A} / \mathrm{cm}^{2}\right)$. Since Ta oxidation is highly exothermic, ${ }^{13}$ this suggests the formation of an insulating oxide layer by extracting $\mathrm{O}$ from the substrate. As with $\mathrm{Au}$, the Ta contacts' thermal stability is consistent with the low defect concentrations evident from DRCL spectra and the major effect of such defects on electrical properties.

Figure 3 shows a similar qualitative difference in spectral features between $\mathrm{Au}$ and Ta contacts on high defect $\mathrm{ZnO}$. For both metals, the bare $\mathrm{ZnO} R=I$ (deep level)/I (NBE) intensities are $\geqslant 1$. Au deposition increases 2.1 and $3 \mathrm{eV}$ emissions, which increase proportionally with annealing. At $650{ }^{\circ} \mathrm{C}, 2.1 \mathrm{eV}$ defect emission again dominates. In contrast, both 2.1 and $2.5 \mathrm{eV}$ emissions are evident for Ta diodes, with spectra dominated by $2.5 \mathrm{eV}$ emission for intermediate temperatures, as with Fig. 1(b). However, unlike Fig. 1(b), the balance of 2.1 vs $2.5 \mathrm{eV}$ emissions reverses at $650{ }^{\circ} \mathrm{C}$. These defect changes are reflected in corresponding $I-V$ spectra shown in Fig. 2(c). Here, Fig. 2(c) displays the initially rectifying characteristics, corresponding to a $0.43 \mathrm{eV}$ barrier $(n=3.70)$. However, this barrier degrades steadily with elevated temperatures starting with $350{ }^{\circ} \mathrm{C}$. Likewise, Fig. 2(d) displays initially Ohmic features that become blocking only at $450{ }^{\circ} \mathrm{C}$. The oxide layer responsible for this blocking is evident from the $5 \mathrm{keV}$ DRCL spectra [inset of Fig. 3(b)], displaying new emission at $\sim 4.1 \mathrm{eV}\left[\mathrm{Ta}_{2} \mathrm{O}_{5}\right.$ band gap $\sim 4.2 \mathrm{eV}$ (Ref. 14)] that appears only after the $550{ }^{\circ} \mathrm{C}$ annealing. Significantly, this blocking feature degrades with $650{ }^{\circ} \mathrm{C}$ annealing (leakage current increases by $\sim 10^{5}$ ) and this $4.1 \mathrm{eV}$ emission disappears. Coupled with the increased 


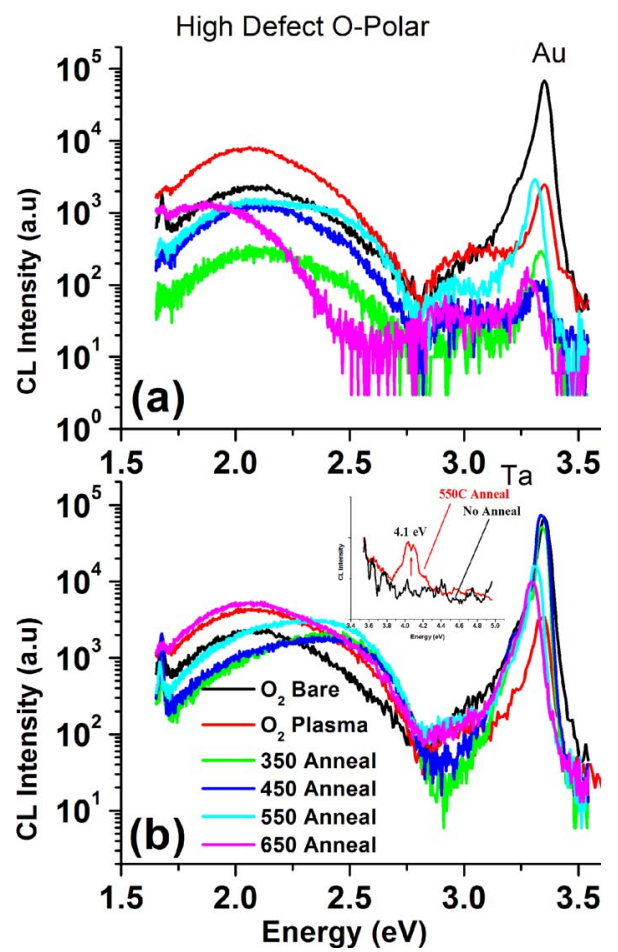

FIG. 3. (Color online) $5 \mathrm{keV}$ DRCLS of $30 \mathrm{~nm}$ (a) Au and (b) Ta on high defect $(000 \overline{1}) \mathrm{ZnO}$. Intense 2.1, 2.5, and $3.0 \mathrm{eV}$ emissions are dominated by $\sim 2.1 \mathrm{eV}$ emission for Au diodes at $650{ }^{\circ} \mathrm{C}$. For Ta contacts, the $2.5 \mathrm{eV}$ intensity increases with $\mathrm{Ta}$ deposition and subsequent annealing up to $550{ }^{\circ} \mathrm{C}$. The inset shows $\sim 4.1 \mathrm{eV}$ peak associated with Ta oxide that appears only at $550{ }^{\circ} \mathrm{C}$.

defect emissions in Fig. 3(b), these changes suggest that the oxide layer becomes less insulating as additional nearinterface defects form.

For both high and low defect $\mathrm{ZnO}$, Au and Ta contacts produce qualitatively different DRCLS and $I-V$ features. Similar differences are evident for Pd and Pt which, as with $\mathrm{Au}$, alloy with $\mathrm{Zn}$ at elevated temperature, versus $\mathrm{Al}$ and $\mathrm{Ir}$, which, as with Ta, form oxides. ${ }^{15}$ Thus the increased 2.1 (2.5) $\mathrm{eV}$ emissions for $\mathrm{Au}(\mathrm{Ta})$ can be associated with $\mathrm{Zn}$ (O)-deficient defects near the metal interface. Furthermore, Figs. 2(c), 2(d), and 3 demonstrate that high defect $\mathrm{ZnO}$ has lower thermal stability for both $\mathrm{Au}$ and Ta contacts. Taken together, these results demonstrate that metals on $\mathrm{ZnO}$ form thin interfacial alloy or oxide layers whose nature depends on thermodynamic driving forces. These interfacial layers require either $\mathrm{Zn}$ or $\mathrm{O}$ atoms from the $\mathrm{ZnO}$, resulting in $\mathrm{Zn}$ or O-deficient layers near the interface only nanometers thick. For $\mathrm{Au}$ on low defect $\mathrm{ZnO}$, the Schottky barrier remains stable and alloying begins only at temperatures above the known eutectic, while for high defect material, the Schottky barrier degrades steadily as resident defects redis- tribute. The $\mathrm{Zn}$-deficient emission dominates only above the eutectic temperature. For $\mathrm{Ta}$ on low defect $\mathrm{ZnO}$, a blocking layer associated with O-deficient defects forms at low temperatures and remains stable with increasing temperature, while for high defect $\mathrm{ZnO}$, the contact is Ohmic up to intermediate temperatures and its $550{ }^{\circ} \mathrm{C}$ blocking layer becomes leaky at higher temperatures. This contrast between low and high defect $\mathrm{ZnO}$ contacts and their defect emission demonstrates that the presence of high defect concentrations promotes interface alloying and reactions that produce additional defects that, in turn, degrade Schottky barriers and blocking layers. In order to achieve high Schottky barriers or blocking layers, defects at the intimate metal-ZnO interface must be minimized. For alloying metals such as Au, subeutectic temperatures are required to preserve Schottky barriers. For oxidizing metals such as Ta, temperatures must be high enough to promote oxide thicknesses sufficient to block current without concomitant defect concentrations high enough to disrupt this layer.

The authors gratefully acknowledge the support for this work by National Science Foundation under Grant No. DMR-0513968 (Verne Hess) and AFRL under Contract No. FA8650-06-D5401 (J. Zetts).

${ }^{1}$ S. J. Pearton, D. P. Norton, Y. W. Heo, L. C. Tien, M. P. Ivill, Y. Li, B. S. Kang, F. Ren, J. Kelly, and A. F. Hebard, J. Electron. Mater. 35, 862 (2006).

${ }^{2}$ D. C. Look, J. Electron. Mater. 35, 1299 (2006).

${ }^{3}$ Y. M. Strzhemechny, H. L. Mosbacker, D. C. Look, D. C. Reynolds, C. W. Litton, N. Y. Garces, N. C. Giles, L. E. Halliburton, S. Niki, and L. J. Brillson, Appl. Phys. Lett. 84, 2545 (2004).

${ }^{4}$ H. L. Mosbacker, Y. M. Strzhemechny, B. D. White, P. E. Smith, D. C. Look, D. C. Reynolds, C. W. Litton, and L. J. Brillson, Appl. Phys. Lett. 87, 012102 (2005).

${ }^{5}$ L. J. Brillson, H. L. Mosbacker, M. J. Hetzer, Y. Strzhemechny, G. H. Jessen, D. C. Look, G. Cantwell, J. Zhang, and J. J. Song, Appl. Phys. Lett. 90, 1 (2007).

${ }^{6}$ H. C. Ong and G. T. Du, J. Cryst. Growth 265, 471 (2004).

${ }^{7}$ A. F. Kohan, G. Ceder, D. Morgan, and C. G. Van de Walle, Phys. Rev. B 61, 15019 (2000).

${ }^{8}$ F. Tuomisto, K. Saarinen, D. C. Look, and G. C. Farlow, Phys. Rev. B 72, 085206 (2005)

${ }^{9}$ L. S. Vlasenko and G. D. Watkins, Phys. Rev. B 71, 125210 (2005).

${ }^{10}$ A. Janotti and C. G. Van de Walle, Appl. Phys. Lett. 87, 122102 (2005).

${ }^{11}$ E. A. Brandes, Smithells Metals Reference Book, 6th ed. (Butterworth, London, 1983), Chap. 11, p. 94.

${ }^{12}$ K. Ip, G. T. Thaler, H. S. Yang, S. Y. Han, Y. J. Li, D. P. Norton, S. J. Pearton, S. W. Jang, and F. Ren, J. Cryst. Growth 287, 149 (2006).

${ }^{13}$ O. Kubaschewski, C. B. Alcock, and P. J. Spencer, Materials Thermochemistry, 6th ed. (Pergamon, New York, 1993), p. 312.

${ }^{14}$ C. Chaneliere, J. L. Autran, R. A. B. Devine, and B. Balland, Mater. Sci. Eng., R. 22, 269 (1998).

${ }^{15}$ H. L. Mosbacker, S. K. El Hage Ghonein, M. Gonzalez, S. A. Ringel, M. Hetzer, D. C. Look, G. Cantwell, J. Zhang, J. J. Song, and L. J. Brillson, J. Vac. Sci. Technol. B 24, 1405 (2007). 